Wheeler, of the English Hospital in Jerusalem, agreed to admit the child for operation. An exploratory puncture revealed a thick, brownish fluid and hygroma was diagnosed. Having fully explained the risks of leaving the growth as it was and also of operation, the friends made all preparations for the funeral, having before this made up their minds that the child could not survive in any case. After some days in hospital I removed the growth under chloroform by two elliptical incisions, leaving abundant flaps. The contained fluid measured over three pints. The need for speed was quite as great as in pre-chloroform days, for though the loss of blood was not great there was sudden collapse from which, however, the patient rallied. The size of the incision may be judged from the illustration; it extended downwards to the anus. The edges were quickly brought together by sutures, few vessels needing ligature. The lower end of the wound healed by first intention, the upper part oozed for some time, but at no time was there any serious rise of temperature. A minute sinus remained for a while after this. No attempt was made, of course, to remove the hygromatous mass firmly adherent to the sacrum. When seen ten months later the child was doing well so far as the operation went, but was considerably pulled down by fever and had an enlarged spleen. It would, of course, be possible at a later date to produce a more "cosmetic" effect. I have to thank Dr. Wheeler for admitting the child and for his help at the operation.

Ramallah, Jerusalem.

\section{RECOVERY AFTER TAKING OVER 40 GRAINS OF PERCHLORIDE OF MERCURY.}

\section{By Pelham C. Mattland, M.R.C.S. Eng.,} L.R.C.P. LOND.

IN answer to a hasty summons from a much perturbed husband to come at once to see his wife, who had swallowed some poisonous tabloids, I found she had dissolved five tabloids of hydrargyri perchloridum in a cup of water and drank the whole. This would amount to $43_{ \pm}^{3}$ grains, each tabloid containing $8 \cdot 75$ grains. This, from searching inquiries and questionings, I have not the slightest reason to doubt was true. I took away the cup with the drainings and found after testing with iodide of potassium a plentiful precipitate of biniodide of mercury. They were the ordinary tabloids, given by another medical man for injection. I found the woman very ill, quite prostrate, vomiting, with abundant diarrhcea. At once, after finding out the nature of the case, I gave about four ounces of carron oil made with oleum morrhuæ as the only oil available quickly. This I followed with one ounce of vinum ipecacuanhæ. I then dispatched the husband for eggs and milk. These being obtained after a time, the whites and milk were given. As there was such a large quantity of the poison I feared the after effects and gave rather a bad prognosis. I was compelled by engagements to leave the case, but I told the husband what to do, and if necessary, or in certain circumstances, as severe prostration, to call in another medical man, as I could not return that night. On the next morning I found the patient-in spite of some pain and prostration, due partly to the remedies employed-comparatively convalescent. In a day or two, with bismuth and tinctura opii and emollient feeding, she quite recovered.

Shepherd Market, Mayfair, W.

\section{NOTE ON A CASE OF BRADYCARDIA.}

By Charles Edmund McDade, M.D. R.U.I., D.P.H.

THE following note on a case of bradycardia unattended with any manifest disease and ending in recovery may prove interesting.

The patient was a man, aged 72 years, who had led a very active life as a public speaker. His health had been good until recently and his family history was also good, with longevity on the maternal side. In July, 1904, he complained of slight giddiness, which yielded to soda, nux vomica, and carminatives. His pulse was then 65 per minute, strong, and regular; his tongue was clean, his appetite was good, and his bowels were regular. The following February he had the same trouble, which soon passed off with the same treatment. On Jane 2nd I saw him again. His pulse was now 40 per minute, but strong and quite regular. He could speak in public as usual, but any physical exertion required an effort quite unusual to him. In walking he felt that he must stop at times although his breathing was not at all affected. The heart sounds were clear, the blood-vessels seemed healthy, and the urine was normal. He continued his work as usual, walking as little as possible. On June 23rd his pulse was 78 per minute, strong, and regular. On July 7 th the pulse had again fallen to 40 and was so on the 14 th, when he had to leave home to preside over a large religious congress which involved continuous public work from day to day for three weeks. He performed all this without any great fatigue. I saw him again on August 13th when his pulse was 64, strong, and regular and he felt well except that he did not care for walking. For the following three months he was very fully occupied, speaking in public from six to 12 times each week and travelling all over England. I saw him again on Nov. 13th. His pulse-rate was then 38 . He looked tired but still persisted in his work which was all planned beforehand.

From this time until Dec. 15th I saw him each week on his return home; he appeared to be gradually failing, his pulse falling to 32 per minute, but still strong and regular. On this date he had a sharp attack of diarrhoea during which the pulse became intermittent and varied in rate from 32 to 40 . From Dec. 19th he stayed in bed, and after a few days' rest his condition was as follows. The radial pulse was regular with a rate of 28 per minute, while the jugular pulsation was 56 . At the apex the heart could be heard beating in exact unison with the pulse at the wrist. About one inch nearer the middle line a faint sound could be heard exactly half way in time between each sound at the apex, as if the right ventricle contracted twice as frequently as the left. No intermediate pulmonary second sound could be heard. The breathing was quite normal and there was no cyanosis. The tongue was clean and the bowels were regular. The abdomen was rather tense, giving a tympanitic note as high as the fourth rib on the left side. This flatulent condition disappeared in a fortnight when treated with sulphocarbolate of soda and carminatives.

For the next four weeks he was kept in bed and fed on light nutritious diet. His radial pulse-rate varied from 27 to 32 , but was always strong and regular, while the intermediate sounds heard internal to the apex gradually became more perceptible, and the jugular pulsations were, always just twice the radial pulse-rate. On Jan. 25th, 1906, the urine was loaded with urates and gave a slight haze on boiling. On Feb. 1st the radial pule-rate was 32 , and the pulmonary second sound could now be heard 64 times a minute, the intermediate sound being weaker than the sound which was synchronous with the apex beat. The left ventricle was beating 32 times a minute. On the 4th the intermediate sounds were more pronounced. On the 5 th the radial pulse was 63 per minute, strong, and regular. For the next four weeks it varied from 48 to 80 , only reverting to the condition of bradycardia on one occasion after a sharp attack of diarrhœea.

During February there were several attacks of diarrhoea which were accompanied with a suppression of one beat in seven at the wrist. On two occasions there were two beats missed at the wrist in succession and the patient's head gave a momentary nod each time it did so. A few days after the pulse-rate was restored he complained of a continuous pain on the left side of his head; this eased off when the pulse-rate fell below 65 but was very bad when the pulse-rate was over 75 . When the pain was severe the anterior branch of the left temporal artery felt hard like whipcord, the right side being quite normal. This pain persisted more or less for about a fortnight. The urine was still full of urates and gave a haze on boiling. He was now able to get up each day, his strength returning very slowly. From March 1st the pulse ceased to be intermittent. On March 30 th he was sufficiently recovered to leave home for the seaside and resumed his public work on April 23rd. On April 29th his pulse was 72 , every beat strong and regular, and he felt fairly well. Sir William Broadbent saw him with me on Dec. 28th, 1905, and March 21st, 1906.

Là ;nder Hill, S.W. 